\title{
WHAT COMMUNICATES QUALITY TO THE SPATIAL DATA CONSUMER?
}

\author{
Anna T. Boin*, Gary J. Hunter \\ Cooperative Research Centre for Spatial Information, Department of Geomatics \\ University of Melbourne, VIC 3010, Australia, a.boin2@pgrad.unimelb.edu.au, garyh@unimelb.edu.au
}

KEY WORDS: spatial data quality, consumers, communication

\begin{abstract}
:
For almost 20 years now, spatial data providers have been creating and publishing metadata records for their products. One intention of the metadata, which includes detailed data quality information, is to inform potential consumers about the inherent strengths and weaknesses of the product for the purpose of making informed decisions as to whether or not it is suitable for their use. However, in this research we question whether or not the quality information that is typically provided in such metadata is actually effective. This research employs qualitative research approaches to explore how users of spatial data determine the quality of a dataset. Consumer feedback emails and semi-structured interviews have been analyzed to discover the perceptions, actions and goals of individual data consumers from a range of professional backgrounds. This paper therefore makes two interrelated contributions. The first is the qualitative research strategy which is inductive, contrary to the statistical experimental designs that are traditionally used in spatial data research. The second comprises the findings to date, that are strongly affected by the context in which they have been collected, which suggest to us that determining spatial data quality metrics is not a separable goal for potential consumers. If this is found to be generally true, then the findings have potential benefits not only for consumers-but also for data providers who may be wasting valuable resources providing data quality information in ways that are of little use to their clients.
\end{abstract}

\section{INTRODUCTION}

While the quality of spatial data is important within our industry, such preoccupations are not always reflected in research fields related to end user applications (Goodchild, 2006). Consequently, there is a missing link between the spatial data quality our industry aims to communicate to the consumer, and the information consumers use in practice to overcome the consequences of imperfect data.

In the following section we review the debates in communicating spatial data quality and we conclude there has been little empirical research conducted into how consumers determine fitness for use in a practical sense. Therefore, a broad, exploratory research technique was required to study this phenomenon. Our research technique is predominantly inductive because it starts by asking consumers about their experiences and then uses the findings to induce theories. Section 3 explains that the method includes consumer opinions from two sources, namely interviews with data users from a range of backgrounds and existing feedback emails, while Section 4 describes the overall results of the study and defines certain themes in order to describe the consumers' experiences to the reader.

Components of these experiences are summarized in section 5 using a conceptual model developed by the authors. The model explains that the consumers tended to determine a perception of product reliability through their own experiences-rather than relying on quality information metrics from the data provider. Finally, the paper closes with the suggestion that data providers could more effectively communicate the quality of their products if quality information were in the form of descriptive data content and opinions from other consumers.

\section{BACKGROUND}

Spatial data is inherently uncertain (Couclelis, 2003). It is the nature of our society that everything is interpreted and that the same reality is inherently likely to be modelled differently by different people (Bédard, 1987). Bédard moves on to argue this uncertainty must be either reduced by more concise classification or absorbed by someone taking on the risk. If, however, we all model reality differently, then it is unlikely that uncertainty will ever be fully eliminated. It therefore follows that data consumers will always be exposed to data uncertainty in some form. They need, however, some idea of the quality of the data they are about to use to make informed choices towards reducing or absorbing that uncertainty.

\subsection{Spatial data quality for the consumer}

In an aim to express uncertainty, standards such as ISO 19113, 19114 and 19115 (ISO, 2002; 2003a; 2003b) summarize quality into the well-known elements of lineage; positional accuracy; semantic, thematic or attribute accuracy; temporal accuracy; logical consistency and completeness. However, little research has been conducted into how these match with the data consumers' concepts of quality or their understanding of the terminology itself. Devillers and Jeansoulin (2006) depicted these elements of spatial data quality as descriptions of internal quality - that is, they relate to the integrity of the spatial database. In contrast, external quality is concerned with the needs of the consumer and is hence related to fitness for use (Chrisman, 1984). When metadata standards indicate that the quality elements should be communicated to end users, they imply that internal quality is required to determine fitness for use, yet there is no empirical evidence of data consumers making practical use of these metrics.

Indeed, we believe there is no empirical research relating to

\footnotetext{
* Corresponding author
} 
how people perceive and use spatial data quality information for individual datasets in a real world environment. Accordingly, the challenge in this research is to determine what information conveys fitness for use to a data consumer who does not necessarily have formal training or education in spatial information theory. As such, it is a search for strategies and terminology to portray these important concepts to those who will be required to absorb any risk associated with use of the data.

Devillers and Jeansoulin, (2006) argue that fitness for use relates specifically to each individual use case, and other anecdotal debates in the spatial industry consequently suggest that providing generic quality information is usually unhelpful to consumers. This research, however, contends there are ways that the details of spatial datasets can be made more comprehensible, even if there is no single overarching solution to the problem. While Frank (1998) suggests this burden is high when expressing lineage, this paper will reveal that other aspects of information quality are similarly hard to understand for the studied consumers. Indeed the terminology that describes the spatial information itself can be confusing. Furthermore we believe that quantities expressing the accuracy of data often fail to contribute to consumer understanding.

\subsection{Choice of an appropriate research techniques}

Research into quality visualization (McGranaghan, 1993; Kardos et al, 2005) has included methods for clearly displaying multiple dimensions of measurements. These assume that quality is quantifiable, which is conceivably true for positional accuracy. It quickly looses relevance, however, for the other semantic aspects of the data and data model and there is no elegant list of independent variables on which to base a statistical assessment. The challenge, therefore, is to find a solution when no single composite method of display can be validly tested for success.

Therefore this research contrasts itself with more traditional deductive, experimental designs by employing a qualitative research strategy. Similar approaches have previously been used to explore map making and map use (Suchan \& Brewer, 2000; Wealands et al, 2005). Also, Ahonen-Rainio and Kraak (2005) studied users deciding on fitness for use between datasets in a reduced interaction environment using qualitative methods. Our study, however, investigates consumers' actions and perceptions within their own workplace situation. It therefore examines subjective phenomena and capitalizes on collecting data in an uncontrolled environment.

While the questions asked by the interviewer follow a basic structure, the interview has a conversational atmosphere. The interview can include themes from previously collected data which the interviewer offers to the conversation in order to increase understanding of a concept (Bryman, 2004). In this way, qualitative interviewing aims to develop themes and concepts with little emphasis on how frequently they occur. In fact, counting how many interviews a particular theme occurs in is not a measure of prevalence of the theme. In our research the themes of interest are the perceptions, recalled actions and goals of consumers when they are concerned with determining fitness for use. Sampling need not be random and in the current study, theoretical sampling aims to interview participants who are likely to contribute new themes. Overall, qualitative research approaches can be robust foundations to inform valid statistical test design (Creswell, 2003; Suchan \& Brewer, 2000).
Creswell (2003) offers primary strategies for validating qualitative data, and the following tasks have been incorporated into this research accordingly:

- Triangulate data from different sources by analysing each source independently of the others to verify the overall findings. This has been done in our research using both interview data and feedback emails. While contexts may cause themes to differ, triangulation means looking for coherence amongst the two sets.

- Member-checking by returning written interpretations of the interview to the participant and asking if they feel they were accurately represented.

- Using rich, thick descriptions so that consumers' experiences are imaginable to the reader.

- Include negative or contrary information because not all participants agree.

- Clarify bias of the interviewer. The qualities and inherent mannerisms and expectations of even the most experienced interviewer introduce biases into data. Gillham (2005) suggests the researcher reveal what they expect, hope and would prefer not to find.

In other words, the purpose of obtaining qualitative data is to extract themes and descriptions. While statistical methods reduce phenomena to a finite set of variables, defending validity leaves a statistical and qualitative researcher with the same challenge (Schatzman \& Strauss, 1973). To illustrate this point, imagine an interactive design element which is encased in a software package where users go through a process of familiarization with the software before rating its effectiveness in a laboratory environment where they can focus their full attention on the application. Any claims that the results are valid or can be generalized to a multi-tasking, time poor, real world environment need to be closely examined because the context of use will be vastly different. By concentrating on describing experiences and declaring the contexts, this research allows the reader to make judgments on generalization.

Qualitative data can quickly show signs of theoretical saturation as each new interview yields less new themes. Determining an appropriate number of interviews depends on the homogeneity of responses from interviewees. New themes, however, tend to decrease with each interview. The question of many interviews is sufficient is open to debate, although a study by Guest et al (2006) suggests 12 participants can reveal $95 \%$ of themes if the participants have homogeneous background. Moreover, Nielson and Landauer (1993) use a mathematical model to argue that $80 \%$ of usability themes could be uncovered by six users and the model curve levels out at $90 \%$ after twelve users.

Various research methods were found that would be partially suitable for researching this topic. The aspects of the text in the feedback emails were categorized using content analysis (Weber, 1990). Semi-structured interviews (Bryman, 2004) allow for a handful of topics to be covered but also provide flexibility for the interviewer to make use of unexpected material in the conversation. Basic think-aloud protocol (Hackos \& Redish, 1998) is useful when consumers can be observed while genuinely trying to determine quality of a spatial dataset. In this way, consumers can be encouraged to use the internet and voice their thoughts as they look for their chosen goal. However, determining fitness for use is a sporadic activity that can be hard to forecast. Consequently, this makes it pragmatically difficult for an observer to be present at the right moments. Alternatively, Critical Incident Technique (CIT) 
(Flanagan, 1954; Chell, 1998) is an approach to questioning people on past, rare or unforeseeable events with a distinctly perceived outcome. Consequently, a combination of these methods has been employed.

In essence, a qualitative researcher takes on an apprentice role of learning from the consumers-who are therefore experts in their own perceptions and opinions (Beyer \& Holtzblatt, 1997). Accordingly, the study explores more than one source of data and is faithful to the topic itself rather than the interviewer's own agenda.

\section{METHOD}

\subsection{Analysing Feedback Emails}

Feedback emails received from customers by the major Statebased mapping agency, Department of Sustainability and Environment (DSE), Victoria, Australia were analysed in our research. In November 2005, more than 500 emails were inspected with some dating back as far as 2002. The feedback came from (a) customers replying to the email which they received when the datasets they ordered were sent to them, and (b) to the customer feedback link on the data producer's website.

The analysis has only examined the emails sent to these addresses and not the subsequent producer's replies or customer emails sent directly to data provider employees. While many customers wrote emails about subjects of concern such as a section of the website being unavailable, payment problems or delivery logistics, about 100 emails were found relating specifically to what we would understand to be quality issues. Half of these concerned the systematic absence of attribute information from a particular data format and the remaining 50 emails were selected for qualitative analysis.

\subsection{Recruiting interview participants}

In addition to the emails examined, we also conducted interviews with spatial data consumers who were recruited from the distribution list provided by DSE and from a call for interview participants placed on the Land Channel website of DSE. The aim was to make contact with data consumers who did not have expertise in spatial information.

Six of the participants would fit into this category, though the cartographer and municipal council employee held positions in the spatial industry. Meanwhile the technician and archaeologist appeared very competent in using spatial data. Both spatial industry members showed an awareness of metadata being a document which conventionally accompanies a dataset, yet their practical attitudes were comparable to those without expertise in spatial information.

Furthermore, while initial interviews revealed many new themes, the rate of new themes occurring was quickly disappearing after ten interviews so our emphasis in future will be on adding detail and encouraging consumers and peer auditors of the raw interview data to comment on the findings to date.

\subsection{Interview Procedure}

The interview process was semi-structured and the participants began with the knowledge that the interview would be about spatial data quality. Typically, they agreed to an audio recording being taken of the interview, but this was not always possible so notes were made. Our first interview schedule used the terms 'fitness for use' and 'quality' in the interview questions, however we quickly discovered that even these apparently simple (to us) terms can be highly theoretical and mysterious to a data consumer.

The interview process therefore began by asking participants what datasets they have been using without restricting them to discussing data from any one particular agency. They were then asked "How they determine whether a dataset is suitable or meets their needs or is good enough" for their purposes. Care was taken here that the interviewer's initial use of vocabulary was restricted, allowing terminology to be first introduced by the participant and then used by both parties.

While these discussions started with conversations about general interaction, the interviewer would also prompt using CIT. If consumers raised an existing question they had about fitness for use, the interviewer switched to basic 'think aloud' protocol using the Internet at the interview location if available. Where appropriate in the dialogue, the interviewer would introduce academic theories and opinions from previous interviews. The consumers were encouraged to debate these ideas to help them articulate their opinion.

Sessions typically lasted one-hour and towards the end of the time, they were asked what their experiences were with the provided metadata for data products they had used. Where possible, this occurred in front of a computer using, again, impromptu 'think aloud' protocol. At this stage, they were also asked to define some terms in their own words such as 'metadata', 'lineage' and 'fitness for use'. The participants were thanked for their time and input, but the contact was not concluded. The interviewer then instigated member-checking by summarizing the interview data typically within 24 hours. A written document was returned to the participants to confirm that their opinions were perceived correctly.

\subsection{Triangulation of the results}

In comparison to consumer interviews, the feedback emails represent a subset of the quality determination process. Indeed, the feedback emails are much more concise and are offered in a context where the consumer usually requires a response or feels a need to defend their own actions.

On the other hand, interviews have a neutral tone. While some consumers volunteered to be interviewed because they had a particular strong opinion about data quality, the interviewer also had the opportunity to ask them about other aspects of their experience with data quality. Both sets of data therefore vary in content and insight but both were analysed separately to identify themes. Conclusions can nevertheless be drawn from both sets of data. The next section of the paper reports on results from both forms of data.

\section{EXPERIENCES OF THE DATA CONSUMERS}

The findings in this section indicate that the consumers' goals predominantly relate to finding out about the data content, then using the data. While perceptions and issues relating to quality play a role in this activity, they tend to be more of a consequence than being the primary aim of the user. The influences of the activities and perceptions gained are 
summarized in Figure 1 and discussed in the next section.

The backgrounds of each interviewed participant are itemized in Table 1, but little background information is available for the writers of the feedback emails. Nine of the ten participants interviewed are living in Victoria, Australia, where government data tends to be sold to consumers rather than being freely available. Australia also has a low population density and there is not always a wide range of spatial datasets to choose from for a specific use. However, given the prevalence of the internet, GPS and other technologies, there are commonly alternative sources of data available.

\begin{tabular}{|c|}
\hline $\begin{array}{l}\text { An architect who has been working in the field for five years } \\
\text { and habitually uses a few data sources to create plans }\end{array}$ \\
\hline $\begin{array}{l}\text { A social researcher from an environmental science } \\
\text { background who now needs data to study people and their } \\
\text { geographic location in relation to retail outlets }\end{array}$ \\
\hline $\begin{array}{l}\text { An acoustic analyst who has used the Internet and university } \\
\text { libraries to understand noise emitted by machinery and } \\
\text { sometimes requires large scale map information to determine } \\
\text { the shape of the land and possible noise sources }\end{array}$ \\
\hline $\begin{array}{l}\text { A municipal council employee in charge of land } \\
\text { contamination data in the United Kingdom. He has ongoing } \\
\text { access to historical data for at least the last hundred years and } \\
\text { is also a data producer }\end{array}$ \\
\hline $\begin{array}{l}\text { A real estate agent in a fast growing suburb who needs data } \\
\text { about properties to estimate sale prices and is subject to } \\
\text { disciplinary action if his estimates are incorrect }\end{array}$ \\
\hline $\begin{array}{l}\text { A cartographer who grew up in the USA and used to publish } \\
\text { maps to illustrate government policies in the US. He is now } \\
\text { producing a state wide paper map in Australia to be used for } \\
\text { a specific recreation while being attractive enough to frame. }\end{array}$ \\
\hline An ecological researcher working in regional Victoria \\
\hline $\begin{array}{l}\text { An archaeologist whose most resent interest was matching } \\
\text { shipping routes with evidence of human presence. His } \\
\text { experience with datasets has evolved over time and various } \\
\text { projects to the extent he now has comprehensive practical } \\
\text { knowledge of coordinate systems and GPS. }\end{array}$ \\
\hline $\begin{array}{l}\text { A technician in a university who, transforms and } \\
\text { disseminates data to students and is trained in nautical } \\
\text { navigation }\end{array}$ \\
\hline $\begin{array}{l}\text { A land owner planning to build a house who is required to } \\
\text { submit plans to the council. He is competent with technical } \\
\text { drawing software and is therefore using electronic data to } \\
\text { create the plans. }\end{array}$ \\
\hline
\end{tabular}

Table 1: The backgrounds of data consumers interviewed.

The experiences of those interviewed are organized according to three approaches the consumers appeared to take when talking about fitness for use. They would report what they had looked for, the conclusions they had come to and the factors that lead them to decide whether or not to use a given dataset.

The vocabulary in this section has been chosen to reflect the terminology used in the interviews. The data are labelled as follows to represent the source type:

[Q]: Quotes are direct verbal accounts copied from interview transcripts or additions made to a member checking document by the interviewee.

[V]: Verified indicates experiences communicated in interviews but better expressed by the researcher in the member checking document which the interviewee verified.

[E]: Emails are direct quotes from feedback emails.

\subsection{What the consumers looked for}

\section{Theme: Comparing}

The architect interviewed had a few data facilities which she and her colleagues used by convention. When asked how she determined the data was good enough:

"(1) [She] assumed it was and did not feel that she had found any problems,

"(2) Multiple people are involved in each project so crosschecking should uncover data problems, and

"(3) [The] information will be merged with other sources so anything problematic will show up naturally.

"In effect, the quality of the data is implicit, 'working knowledge,." [V]

Similarly the cartographer stated:

"[I] know where to find secondary sources to correct [a] problem” [Q]

This strategy of looking for comparative consistency in other data is particularly suited to when the consumer has ongoing access to the data. However the acoustic analyst did not have a continuous subscription and yet had a similar strategy. He said he would rather "buy it, download it and then work out" [Q] whether it is suitable rather than actively seeking information about its quality before first use.

Accordingly, all consumers recalled anecdotally crossreferencing data with other sources so as to "visualize where I actually am" [Q]. This consumer used the local, published street directory in raster form "so you can see where all the pathways are” [Q]. Indeed, secondary data sources and sporadic ground truthing were used in some way by all interviewed consumers. In effect, consumers had formed their opinion of a dataset by comparing it with the other data around them rather than benefiting from publicly available statistics. The municipal council employee claimed: "Where there are consequences, verification is done within the organization" [V] even though completing metadata statements was also one of his responsibilities.

\section{Theme: Data content}

Interviewed consumers also looked for more information on feature and attribute definitions. They were trying to determine what attributes meant and did not necessarily find satisfactory answers.

This was a fundamental deciding factor for the acoustic analyst because he could not sufficiently determine what the dataset contained for him to purchase it, and consequently decided on an alternative product.

In feedback emails, customers made requests for data in their own words typically summarizing their requirements and the quality required in one sentence:

"I am searching for a comprehensive gazetteer of Victorian place names that includes up-to-date gazetted localities as well as superseded place names." [E]

Similarly, one email from an engineering company email address began by asking:

"Do you have a sample of what a map [from a particular product line] looks like?” [E] 


\section{Meta Theme: Expectation}

In fact, this summarizes not only a desire to know the extent of the data coverage, but also what to expect. Several conclusions about data expressed in consumer feedback emails relate to whether expectations had been met or not:

"My goal is to obtain a simple contour map of the CBD [Central Business District] of Melbourne ... I did not expect [just] 5 dots and a similar number of lines." [E]

"The info sent so far doesn't satisfy my expectations of a [particular map series] tile ... I have bought many of these [maps] over the years and they have been very useful" [E]

The following feedback email also embodies expectation and refers to data content and a compared data source:

"[The missing walking tracks] are clearly marked on the [other agency's] documents ... there is NO WAY I can tell [whether] the walking tracks ... are marked on your maps or not until after I have purchased them." [E]

Ten of the 50 emails fall under the expectation theme. There is, however, less use of the word in the interview data, though the architect:

"Expect[ed] millimetre accuracy for drawing up plans" [V]

\subsection{Conclusions consumers have drawn}

Conclusions about a dataset can start before the content is even determined and may continue throughout aspects of the usage cycle. In essence, the customer who failed to find easily understood information about the contents of a dataset has drawn conclusions about the suitability before purchasing the data or determining what it contains. However for those who have chosen to obtain a dataset, their conclusive opinions dominantly come from the comparisons they make with other datasets.

\section{Theme: Comparing (continued)}

Issues related to "merging" [E] datasets appeared in feedback emails with many concerns possibly related to coordinate system problems or other descriptions of two datasets obviously not "matching up" [E].

Both the municipal council employee and real estate agent could compare data of the same area over time. Accordingly they both reported noticing areas of data that were included in a product one year but were missing in the next. Their impressions of the implications of this problem, however, differed. While the council employee explained they are "subject to interpretation" [V], the real estate agent found out the housing statistics calculations had changed because "you can ... do the maths in a spreadsheet" [Q]. Moreover, "if somebody has reasonable proof that [the dataset] is wrong, then I'll believe them rather than believe [the dataset]" [Q]

In response to being asked how good the data is, the council employee turned to his computer and:

'Indicate[d] that the data is therefore 'poor' because the 'angles' of the road are 'different', 'don't line up ', [V]

He then considered a second set of aerial photography and:

"Conclude[d] this [was] high quality aerial photography because they 'match' and because the [vector data] is a 'close fit', ' [V]

\section{Theme: Source of the data}

However the council employee cautioned that:
"Maps can fit together well because they are from similar [original] sources. Need to know sources well." [V]

Indeed, this was the first endorsement from a data consumer for a form of lineage information, though use of the term lineage has not yet been used by any of the consumers.

Perceptions of quality became tangible for consumers who reported finding an explanation of how the data was created which described the characteristics of the resulting data:

"There was not a high incidence of correlation until they found out the ... sites had been jotted in pencil on a map with $40 \mathrm{~m}$ accuracy" [V]

Furthermore, an ecological researcher pointed the following section of metadata which he had found by clicking on the title of a map layer of a freely available interactive map:

“... Dense tree cover boundaries will be tangible, physical edges of patches of dense trees and will be observable on ground. ... Scattered tree cover boundaries will not necessarily be physically obvious at ground level. The Dense class: represents tree cover of approximately $80+\%$ density. It has a minimum patch size of 5 hectares (smaller patches will be medium class). And it allows for minimum gaps in tree cover of 0.1 hectares ..."

Although he says he didn't investigate it [much], he [communicated] a good understanding of which configurations of trees (like a few dense trees in a plain) would be evident in the data." [V]

\section{Theme: Reliability}

In a few emails, issues of reliability were evident:

"I have a concern that not all survey information shows up on the system ... The system is not reliable for searching survey information if that is the case." [E]

Similarly, when talking about the consequences if legal data was correct, the real estate agent said the stake holders are:

"Going to be relying on the fact that this is correct" [Q]

Yet regarding the data he uses on a daily basis:

"[I] rely on it to the fact that it should be right. But in fact it isn't and I can't rely on it ... " [Q]

The technician did not mention reliability until the interviewer suggested it, though this lead to a new section of discussion about reliability charts on navigation maps. Reliability was not only the title of the chart but he also used the term repeatedly to describe the chart in his own words:

"It's about the reliability of the data ... it says the data in this particular area was taken in 1853 and therefore fits into the not-too-reliable category” [Q]

On the other hand the archaeologist brought up reliability when asked to define the term 'fitness for use' in his own words. He thought for a moment, and then said:

"Suitability to the task ... and of course the reliability is going to depend on whatever number of factors." [Q]

\section{Theme: Interaction}

Finally, when asked directly what they thought of the notion of data quality, the architect brought up issues related to the interface for accessing the data:

"(1) Having to type in addresses repeatedly even though one task flows on from the previous one, and

"(2) The connection to the Interactive Map is faster and much more reliable than it used to be" [V]

Issues of interaction continue to be discussed below given they were also deciding factors in whether the data would be used. 


\subsection{Some Deciding Factors for Consumers}

\section{Theme: Interaction (continued)}

For those people who search through the Internet, the website is the window to the data. Even a consumer who regularly visited university engineering libraries to search for complementary information found himself in a predicament with spatial dataset terminology:

"If it starts talking jargon ... it's lost me because I can't translate jargon for [my client] who's running a factory if I don't understand it myself." [Q]

Alternatively, after using live information a few times the real estate agent felt:

"[I would] like to have the time and energy to use more of it ... If I had unlimited hours in a day, I'd be right" [Q]

\section{Theme: Reputation}

However some consumers had almost made their choice with little reported influence from the web interface. In these cases, reputation played a significant role in the choice. The cartographer had a similar approach to an academic or librarian where he was interested in using a dataset from 'the authority' despite the internal quality:

"I'll use their data because they are the authority ... even though there are errors and I have reported some errors [to them]" [Q]

Similarly, the technician: "judges the quality of the data by how 'authoritative' the provider is. When asked if there was any information on the web he used to work out whether he could trust the data, he thought for a while, then said:" [V]

" "No, it's trusted by the name of where it comes from. [DSE] is in charge of blocks of land, [I've] read enough about surveying to know it's ... precise ... so I just believe it's right. All I have to do is check my own work'." [Q]

Moreover, the successful GPS coordinate check performed on his own property supported his reasoning. Regardless of whether this perception is correct, this data consumer showed no intention of looking further for information about the quality.

\section{Theme: Cost}

Finally, cost also had significance for consumers. The architect had a financial threshold to spend on data without further paperwork. Similarly, the real estate agent was willing to pay for the data he "can't rely on" [Q] because it was convenient.

The cartographer, however, asserted:

"Data that has a cost can undermine the financial feasibility of publishing a map or map series" [V]

\subsection{Reactions to metadata on the Internet}

Towards the end of each interview, existing metadata was brought to the attention of the participant if they had not already raised it as a topic.

The authors are surprised that so far no reported use has been made of lineage information, attribute accuracy or logical consistency. While our detailed, contextual data only includes ten interviews, those interviewed come from varied backgrounds with contrasting levels of experience. Moreover, analysis has been triangulated with 50 emails related to data quality and at least 100 emails related to data acquisition.

Furthermore, there was no express frustration regarding the metadata itself but rather a tendency to automatically ignore it, along with any other confusingly displayed pages on the web. In some cases, participants were introduced to the metadata page by the interviewer. They generally found the information confusing. One academic researcher referred to metadata text stating "attribute accuracy ranges between a $1 \%$ to $5 \%$ error" and commented:

"I'm probably not up with it enough to know what is and what isn't high quality" [Q]

Similarly, the architect looked at it for a few seconds, then:

"She said under normal circumstances, she would have left the page after a few seconds because it made no sense to her" [V]

When we started the data collection process, we expected to find at the very least that (1) quality was a data concept that the consumer was aware of, and (2) a frustration that the current quality statements in metadata were hard to understand. The forecast challenge was to suggest more understandable language and include graphical representation. Although interviews were conducted with an impartial approach, we would have preferred to find that quality was important to the consumer and would have hoped not to find that people have already found other ways to decide whether data is fit for their use that are satisfactory to them. These findings have therefore evolved in spite of our biases.

\section{A CONCEPTUAL MODEL FOR REAL WORLD DETERMINATION OF SPATIAL DATA QUALITY}

Overall, standardised metadata has not played a significant role in data consumers' perception of the data, yet they have still established opinions of the data quality. These experiences of data consumers indicate that quality was communicated to the interviewed data consumers as a gradual process of reasoning. Decisions to purchase or try using a dataset were of course made, but determining whether the data was suitable, good enough, or reliable was a process which continued after the data was obtained.

Accordingly, this section introduces a conceptual model to capture the influences on perception that have occurred for the interviewed consumers (Figure 1). The model depicts there are three major, discrete paths in finding a dataset to use:

1. Interaction as a barrier: Consumer needs data, uses the internet, interacted with a website which sold spatial data, finds the terminology or the site architecture confusing or time consuming. He or she gives up and decides the data is not suitable.

2. Content and cost: Consumer needs data, uses the internet, determines data content and decides whether the data is suitable. If yes, use is made of the data and additions and comparisons are made with other information. He or she then determines an impression of the data reliability.

3. New consumer: Instead of searching on the internet, the consumer consults friends and colleagues or other queues from their environment to choose data by its reputation. Meanwhile this reputation may have been influenced by consumers who have previously used the data. 


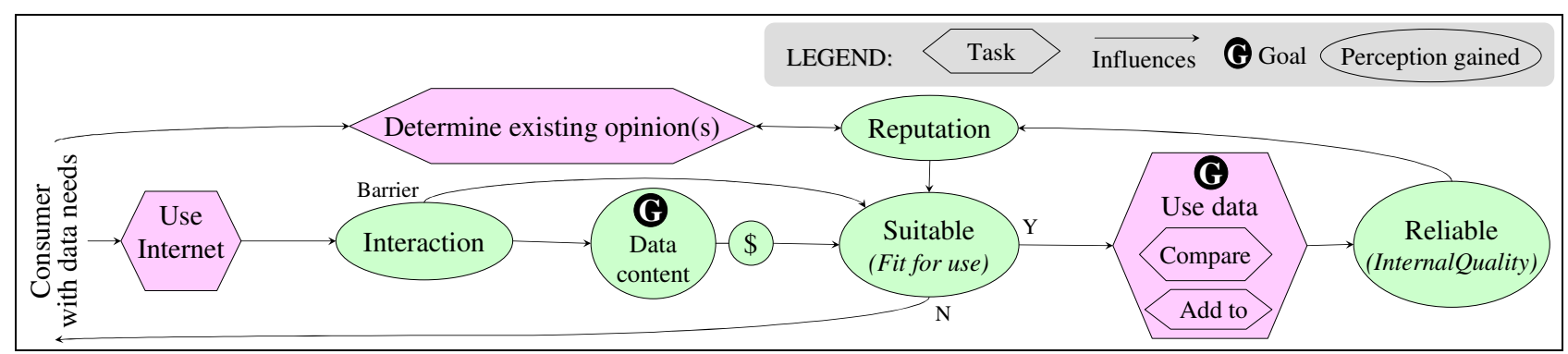

Figure 1: A conceptual model of how consumers determine spatial data quality.

Furthermore, there are two major goals that this model includes. The first is to determine what the data contains and the second is to make use of it. In the process of achieving these two goals, consumers will gain perceptions of both fitness for use and internal quality, however, they will do so using information and reasoning which may or may not be supplied by the data provider.

In this way, the model aims to place the purchasing of data via the internet into context. Consumers who use the web will first gain perceptions of the terminology and website architecture. They will only determine what the dataset contains if the dataset is described in language they understand on web pages they can find. Moreover, query mechanisms need to be clear and timely. Their goal, however, is determining data content which is the prime opportunity for quality to be communicated. Accordingly, the tree cover density description the ecological researcher found was more detailed information about the dataset. Similarly, one email asked not for any place names, but for a comprehensive gazetteer with current and historic place names included. She may seek metadata to determine, whether a given dataset meets her definition of comprehensive and current, but then again she may not.

\section{Expectations}

Communicating spatial data quality in terms of consumer goals contributes towards managing expectations. Emails on expectation, however, also gave specific emphasis to the particular coverage the consumer was purchasing. Therefore, we suggest providing statistics on the volume of data about to be purchased. Such information would include a thumbnail image of the data, bounding coordinates expressed in the coordinate system being purchased, number and volume of files or tables. Figure 2 shows one prototype of this information.

\section{Opinions of other purchasers}

Data use is the second goal. This is depicted as occurring after the Internet has been used, however use influences impressions of reliability which in turn influence reputation. Meanwhile these impressions previous consumers have formed could be included on websites as consumer opinions. Indeed, similar models to the book reviews on Amazon.com as suggested by Duval and Hodgins (2004) and Gould (2005). Consequently, Figure 2 has a link to opinions from other purchasers.

\section{Source of the data and updates to the paper}

Source of the data is only one of several comparable themes which also appeared in analysis. Others include how complete and how up to date the data might be. These are yet another detail in expressing the data content and an early prototype is shown in Figure 3. This is not lineage because it does not itemize each stage of creation. Rather, it gives detailed examples of how such origins might manifest themselves in the end product. While these terms are comparable to metadata quality elements, the consumers appear to be more interested in anecdotal descriptions rather than statistics.

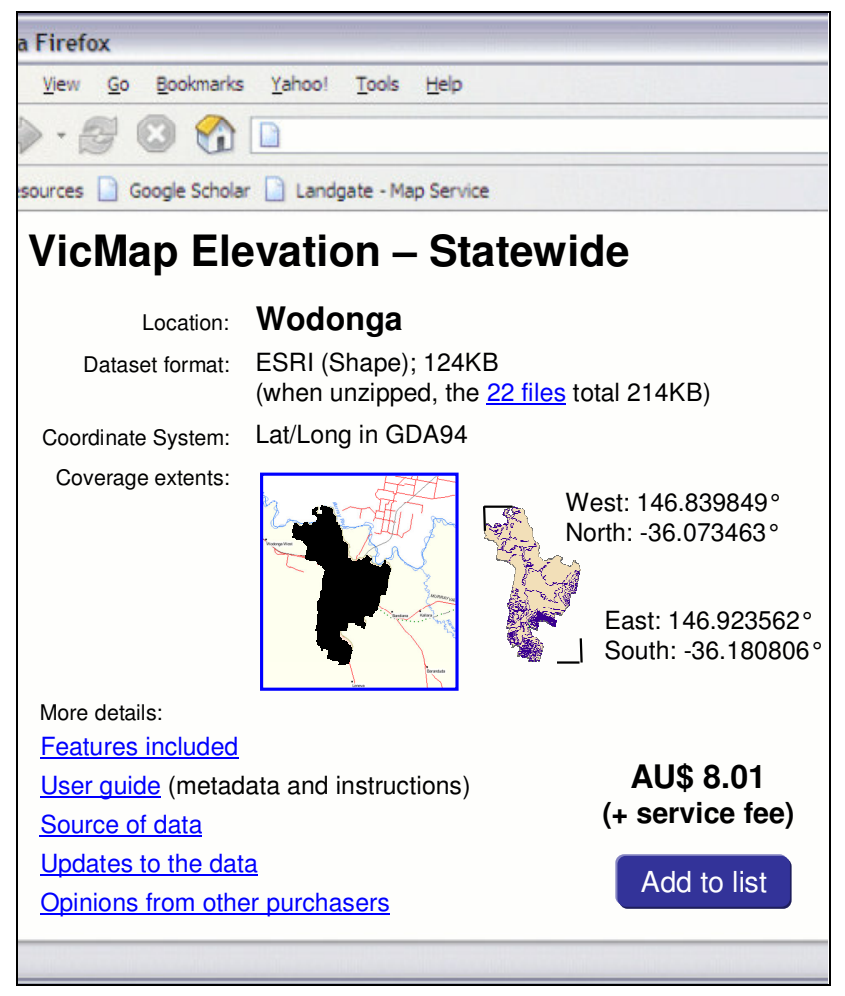

Figure 2: A prototype for managing expectations

Regional updates:
1950-1980 maps
Traced from 1:10,000 maps
Data was digitized from the topographic map base,
approximately half this area has been corrected for drainage
using ANUDEM in 1999, but no new observations included.
5m vertical accuracy.

Figure 3: Partial image of prototype page for source of the data

\section{CONCLUSIONS}

This paper induces such reasoning from qualitative data. The strength of this data is that it provides context and detail to the studied phenomenon. In this way, the understanding of individuals' experiences can be accumulated and developed by the researchers. While it is not objective, neither are consumers' perceptions. Instead, it is reflexive because it acknowledges the 
researchers' attitudes and expectations. The reported results include only a subset of themes collected so far, and they must also be viewed as a collection of themes in the context in which they were collected.

This research has investigated the experiences of the every-day consumer of spatial data in determining whether a dataset is fit for use. Explorations have led to conversations with consumers from both spatial and non-spatial backgrounds. The study found the consumers were more interested in finding out what the data contained and how it matched with other information than statistical metrics of internal quality. We therefore suggest that the data purchasing process considers 'fitness for use' to be a management of expectations. Two approaches need to be taken towards this process. Firstly, quality information should be added by enhancing descriptions of the data content. Secondly, insights into others' experiences of using the data need to be made available by including opinions of other purchasers.

\section{ACKNOLWEDGEMENTS}

This work has been supported by the Cooperative Research Centre for Spatial Information, whose activities are funded by the Australian Commonwealth's Cooperative Research Centres Programme.

\section{REFERENCES}

Ahonen-Rainio, P. and M.-J. Kraak (2005). Deciding on fitness for use: evaluating the utility of sample maps as an element of geospatial metadata. Cartography and Geographic Information Science, 32(2), pp. 101-112.

Bédard, Y. (1987). Uncertainties in Land Information Systems Databases. In: Eighth International Symposium on ComputerAssisted Cartography, Baltimore, Maryland.

Beyer, H. and K. Holtzblatt (1997). Contextual Design: A Customer-Centered Approach to Systems Designs. London, New York, Morgan Kaufmann.

Bryman, A. (2004). Social Research Methods (2nd ed.). New York: Oxford University Press.

Chell, E. (1998). Critical Incident Technique. In Qualitative Methods and Analysis in Organizational Research (pp. 51-72). London, Great Britain: SAGE.

Chrisman, N. R. (1984). The role of quality information in the long-term functioning of a geographic information system. Cartographica, 21(2 \& 3), pp. 79-87.

Couclelis, H. (2003). The Certainty of Uncertainty: GIS and the Limits of Geographic Knowledge. Transactions in GIS, 7(2), pp. $165-175$.

Creswell, J. W. (2003). Research Design: Qualitative, Quantitative and Mixed Methods Approaches. Thousand Oaks, CA, Sage.

Devillers, R. and R. Jeansoulin (2006). Spatial Data Quality: Concepts. Fundamentals of Spatial Data Quality. R. Devillers and R. Jeansoulin (Eds), ISTE, London, pp. 31-42.

Duval, E., \& Hodgins, W. (2004). Metadata Matters. Accessed 10 Sept 2005, from
http://www3.uji.es/textasciitilde\{\}gould/metadatos/DuvalHodg insDC2004-preprint.pdf

Flanagan, J. C. (1954). The Critical Incident Technique. Psychological Bulletin, 51(4), 327-358.

Frank, A. (1998). Metamodels for data quality description. Data Quality in Geographic Information: From Error to Uncertainty. M. F. Goodchild and R. Jeansoulin (Eds), Hermes.

Gillham, B. (2005). Research Interviewing: the range of techniques. New York: Open University Press.

Goodchild, M. F. (2006). Forward. Fundamentals of Spatial Data Quality, ISTE, London, pp. 13-16.

Gould, M. (2005). Geospatial Metadata Part 2. GEO:connexion, $\begin{array}{llll}\text { Accessed } & 12 & \text { October 2005, from }\end{array}$ http://www.geoconnexion.com/magazine/article.asp?ID=2253

Guest, G., A. Bunce, et al. (2006). How many interviews are enough? An experiment with data saturation and variability. Field Methods 18(1), pp. 59-82.

Hackos, J. T., and Redish, J. C. (1998). User and task analysis for interface design. New York: John Wiley \& Sons, Inc.

ISO 19113, 2002. ISO 19113:2002 Geographic InformationQuality Principles. International Organization for Standardization: Geneva, Switzerland.

ISO 19114, 2003, ISO 19114:2003, Geographic informationQuality evaluation procedures. International Organisation for Standardisation.

ISO 19115, 2003, ISO 19115:2003 Geographic InformationMetadata. International Organization for Standardization: Geneva, Switzerland.

Kardos, J., Benwell, G., \& Moore, A. (2005). The Visualisation of Uncertainty for Spatially Referenced Census Data Using Hierarchical Tessellations. Transactions in GIS, 9(1), 19-34.

McGranaghan, M. (1993). A cartographic view of spatial data quality. Cartographica, 30(2\&3), 8-19.

Nielsen, J., and T. K. Landauer. 1993. A mathematical model of the finding of usability problems. Proceedings of INTERCHI 93:206-13.

Schatzman, L. and A. L. Strauss (1973). Field research: strategies for a natural sociology. Prentice-Hall, Englewood Cliffs, N.J.

Suchan, T. A., and Brewer, A. M. (2000). Qualitative Methods for Research on Mapmaking and Map Use. Professional Geographer, 52(1), 145-154.

Wealands, K., Miller, S., Benda, P., \& Cartwright, W. E. (2007). User Assessment as Input for Useful Geospatial Representation within Mobile Location-Based Services. Transactions in GIS, 11(2), 283-309.

Weber, R. P. (1990). Basic Content Analysis (2nd ed.). Newbury Park, California, USA: SAGE Publications. 